\title{
A INFLUÊNCIA DA DIMENSÃO POLÍTICA NO PROCESSO DE SALES AND OPERATIONS PLANNING (S\&OP)
}

\author{
THE INFLUENCE OF POLITICAL DIMENSION ON SALES AND OPERATIONS PLANNING (S\&OP) \\ PROCESS
}

Glauco Ricardo Simões Gomes ${ }^{1}$

\footnotetext{
${ }^{1}$ Msc. (CEPEAD/ UFMG) glaucorsg@gmail.com
}

Resumo: $\mathrm{O}$ artigo teve por objetivo identificar e analisar a influência da dimensão política do processo decisório no contexto do planejamento de vendas e operações (S\&OP). Para tanto, tomando como base teórica a visão relacional e os efeitos do poder nas organizações, aspectos como a formação de coalizões e uso de mecanismos de controle foram ressaltados. Realizou-se um estudo de caso em duas empresas do setor de alimentos cuja coleta de dados se deu a partir de entrevistas semiestruturadas, observação in loco e análise documental. Os dados foram analisados via análise de conteúdo com categorias advindas da literatura e dos relatos dos entrevistados. Apesar das evidências de coalizões com diferentes relações de poder e mecanismos de controle, os resultados mostraram em ambos os casos, a estratégia empresarial como elemento de suporte e legitimação à formação destes grupos e a forte influência das relações interpessoais no acesso aos decisores estratégicos.

Palavras-chave: Dimensão política. Sales and Operations Planning. Formação de coalizões. Mecanismos de controle. Poder nas organizações.

Abstract: The purpose of this article was to identify and analyze the influence of the political dimension of the decision-making process in the context of Sales and Operations Planning (S \& OP). Based on the theories of relational view and power in organizations, aspects such as the formation of coalitions and the use of control mechanisms were highlighted. A case study was conducted in two food companies whose data collection was based on semi-structured interviews, in loco observation and documentary analysis. The data were analyzed through content analysis with categories from the literature and the interviewees' perspectives. Despite the evidence of coalitions with different power relations and control mechanisms, the results show in both cases, business strategy as an element of support and legitimacy for the formation of these groups and the strong influence of interpersonal relations in access to strategic decision makers.

Keywords: Political dimension. Sales and Operations Planning. Coalition formation. Control mechanisms. Power in organizations. 


\section{Introdução}

Este estudo teve por objetivo analisar como características da dimensão política do processo decisório fazem-se presentes na rotina das organizações à luz de suas escolhas estratégicas. Para tanto, buscou-se investigar como os aspectos políticos emergem em meio a um conjunto de decisões críticas das empresas por meio da formação de coalizões e quais os desdobramentos das ações tomadas a partir destas decisões nos resultados organizacionais.

Como locus para a pesquisa optou-se pela análise do processo de planejamento de vendas e operações (ou Sales and Operations Planning - S\&OP). Uma vez que objetiva alinhar os planos estratégicos e táticos da organização mediante a participação (por vezes, conflituosas) de diversos gestores, enxerga-se no S\&OP potencial para a formação de coalizões políticas e a emergência de mecanismos de controle das rotinas organizacionais. De fato, o processo combina pessoas, processos e tecnologias na sua função de balancear demandas planos de suprimento (Jacobs, Berry, Whybark, \& Vollman, 2010; Lapide, 2005). Contudo, Bower (2012) e Jacobs et al. (2010) ressaltam que o S\&OP está intimamente ligado à participação das pessoas. Os autores argumentam ainda, que de modo a alcançar o equilíbrio, é essencial integrar pessoas de diferentes áreas, internas e externas à empresa e fornecer uma plataforma para discussão e tomada de decisão inter e intraempresarial.

Indo de encontro a alguns resultados que definem S\&OP como um processo genérico (Proud, 2007) ou menos dependente de contexto (Grimson \& Pyke, 2007; Thomé, Scavarda, Fernandez, \& Scavarda, 2012), o artigo apoiou-se em gaps relacionados à influência de elementos contextuais (Noroozi \& Wikner, 2017; Thomé et al., 2012) para abordar como a dimensão política "molda" as decisões inerentes ao planejamento de vendas e operações. Em consonância com uma recente corrente teórica que advoga acerca da necessidade de se estudar o S\&OP como um fenômeno dinâmico, decorrente de aspectos contextuais e com características peculiares (Kristensen \& Jonsson, 2018; Noroozi \& Wikner, 2017; Thomé, Scavarda, Pires, Ceryno, \& Klingebiel, 2014), dois fatores puderam ser destacados como base para a adoção desta perspectiva.

O primeiro desses fatores trata da singularidade na aproximação dos temas S\&OP e política. Buscas realizadas nas bases de dados acadêmicas como Periódicos Capes, Scielo e SPELL ${ }^{\bullet}$ envolvendo os termos $S \& O P$, politics, political e suas respectivas variantes em português, retornaram poucos resultados, muitos desses apenas contemplando os termos no seu corpo de texto, porém sem a finalidade objetivada aqui.

O segundo fator preponderante para a escolha do processo de Sales and Operations Planning foi o fato de que este processo apresenta alguns atributos muito particulares, como sua frequência de ocorrência, sua realização por indivíduos da alta e média gerência e sua finalidade de alinhamento entre demanda e suprimentos (Pedroso, Silva, \& Tate, 2016); configurando-o então, como um espaço fértil para a manifestação de elementos da dimensão política do processo decisório, e em particular, a formação de coalizões políticas e a adoção de mecanismos de controle. 
Assim, definiu-se a seguinte questão de pesquisa como orientação para a realização deste trabalho: qual a influência da dimensão política e suas respectivas características como mecanismos de controle e a formação de coalizões influencia o processo decisório do planejamento de vendas e operações (S\&OP)? Contudo, é preciso salientar que analisar o processo decisório de uma organização por si só já se constitui como uma tarefa de grande complexidade e amplitude, haja vista o desenvolvimento teórico do tema desde a década de 1950 em torno de três grandes perspectivas: (i) racionalidade e racionalidade limitada, (ii) política e poder e (iii) garbage can (Eisenhardt \& Zbaracki, 1992).

Logo, este trabalho apoiou-se na perspectiva da política e poder para realizar a análise do processo de S\&OP. Entretanto, não teve a intenção de perpassar por todas as suas facetas e minúcias. Restringindo-se assim, às suas características gerais, ao papel do controle no processo decisório e a noção (e formação) de coalizões internas às organizações (Pfeffer \& Salancik, 2003).

De forma a ilustrar a presença da dimensão política da tomada de decisão intrínseca ao processo de S\&OP, definiu-se como aproximação metodológica para este trabalho o estudo de caso de natureza qualitativa (Godoy, 2010; Yin, 2005). A opção por tal abordagem vem em função da complexidade do fenômeno em estudo e em linha, com a necessidade de incorporação de métodos qualitativos e mistos na pesquisa na área de operações (Dubois \& Salmi, 2016; Fremeth, Holburn, \& Richter, 2016; Golicic \& Davis, 2012).

A coleta de dados contou com análise documental, observação in loco e entrevistas semiestruturadas junto a gerentes e analistas das áreas de produção, logística e vendas em duas empresas industriais do ramo de alimentos e bebidas com atuações nos cenários nacional e regional. Posteriormente, passou-se à análise de conteúdo tendo como categorias de análise elementos das relações de poder e trocas sociais nas organizações (Emerson, 1962; Fontenot \& Wilson, 1997; Molm, 1997) como relações interpessoais e influência, além de aspectos evidenciados pelos próprios discursos dos entrevistados.

Após a presente introdução, o artigo apresenta mais quatro seções. A seção 2 traz o referencial teórico que dá suporte à discussão; sendo subdividido no papel da dimensão política no processo decisório e o processo de planejamento de vendas e operações. A terceira seção apresenta a metodologia utilizada para a construção do artigo, seguida pela análise do estudo de caso (seção 4). Por fim, na seção 5, são apresentadas as conclusões do trabalho, suas limitações e propostas de trabalhos futuros.

\section{Referencial teórico}

Esta seção traz as bases teóricas utilizadas para a construção do artigo. Amparando-se na visão relacional, salientaram-se os elementos da dimensão política do processo decisório (e seus respectivos desencadeamentos, como o poder e o controle dentro das organizações). Adicionalmente, 
discorreu-se sobre o processo de S\&OP praticado pelas empresas industriais, sua dinâmica e importância para os resultados no curto, médio e longo prazos.

\subsection{A dimensão política do processo decisório}

Para Eisenhardt e Zbaracki (1992), a tomada de decisão em seus mais variados níveis é de extrema importância. A decisão de nível estratégico em particular, é tida como crucial, visto que envolve as decisões que vão moldar o curso da empresa. Mintzberg et al. (1976, p. 246) definem a decisão estratégica como aquela decisão tida como importante em termos das ações tomadas, recursos alocados e aspectos precedentes. Royer e Langley (2008, p. 251), em linha com esta visão, adicionam que estas decisões são tipicamente realizadas sob incerteza, envolvem vários decisores e não apresentam soluções pré-programadas.

De fato, a noção de que o processo decisório das organizações não se dá de maneira linear e racional - seja esta racionalidade perfeita ou limitada como em Simon (1965) - há muito vem sendo contestada. A ideia de que a percepção (cognição) do decisor frente a um universo constituído pelo problema a ser tratado (representado aqui pelo conjunto de alternativas viáveis e possíveis soluções) é limitada, levou à configuração de um corpo teórico sobre processo decisório suportado por três perspectivas tradicionais, a saber: (i) racionalidade e racionalidade limitada, (ii) política e poder e (iii) garbage can. A Figura 1 apresenta tais perspectivas, suas características, visões alternativas e principais autores.

Distanciando-se das limitações cognitivas e do pressuposto de um construto monolítico da racionalidade limitada (Eisenhardt \& Zbaracki, 1992) ao mesmo tempo em que se busca uma abordagem que contemple diferentes níveis de análise (algo que não se consegue facilmente no modelo garbage can), este trabalho apoiou-se na perspectiva política para o atingimento de seus objetivos. Em particular, a escolha por esta aproximação baseou-se na importância dada à decisão estratégica por alguns autores. Neste sentido, há de se ressaltar o vínculo entre a política e as decisões estratégicas. Vínculo este, caracterizado como (i) complexo e multifacetado, (ii) passível de disfuncionalidade e (iii) incerto (Elbanna, Kapoutsis, \& Mellahi, 2017; Hiatt \& Sine, 2014; Nutt, 2008; Tsotsolas \& Alexopoulos, 2017). 
Figura 1 - Síntese das perspectivas tradicionais do processo decisório

Perspectiva Principais características Críticas

Principais autores

\begin{tabular}{|c|c|c|c|}
\hline $\begin{array}{l}\text { Racionalidade e } \\
\text { racionalidade } \\
\text { limitada }\end{array}$ & $\begin{array}{l}\text { Baseia-se nas premissas de } \\
\text { que o comportamento } \\
\text { humano apresenta algum tipo } \\
\text { de propósito. } \\
\text { Os atores organizacionais } \\
\text { entram em situações de } \\
\text { decisão com objetivos } \\
\text { conhecidos. }\end{array}$ & $\begin{array}{l}\text { As limitações cognitivas podem } \\
\text { ser percebidas uma vez que os } \\
\text { objetivos perseguidos podem se } \\
\text { mostrar inconsistentes dentre } \\
\text { os atores organizacionais e ao } \\
\text { longo do tempo. } \\
\text { O comportamento dos atores } \\
\text { não é racional (geralmente é } \\
\text { local) e sofre forte influência } \\
\text { dos padrões de procedimento } \\
\text { operacional. }\end{array}$ & $\begin{array}{l}\text { March e Simon (1958) } \\
\text { Cyert e March (1963) } \\
\text { Simon (1965) }\end{array}$ \\
\hline Poder e política & $\begin{array}{l}\text { Tem suas origens na literatura } \\
\text { da Ciência Política da década } \\
\text { de } 1950 . \\
\text { As decisões são o resultado de } \\
\text { um processo no qual os } \\
\text { decisores têm diferentes } \\
\text { objetivos, aliam-se por meio } \\
\text { de coalizões em que as } \\
\text { preferências do mais poderoso } \\
\text { prevalece. }\end{array}$ & $\begin{array}{l}\text { Divergências teóricas ao tratar a } \\
\text { política como um fenômeno } \\
\text { fluido (em que se gerariam } \\
\text { vantagens competitivas a partir } \\
\text { do embate de posições dos } \\
\text { atores) ou estático (em que a } \\
\text { política é resultado de um } \\
\text { vácuo de poder deixado por } \\
\text { atores insatisfeitos com o } \\
\text { processo decisório). } \\
\text { Questiona-se se a política é } \\
\text { vista como parte essencial para } \\
\text { o processo decisório ou algo } \\
\text { disfuncional. }\end{array}$ & $\begin{array}{l}\text { Allison (1971) } \\
\text { Baldridge (1971) } \\
\text { Pettigrew (1973) } \\
\text { Salancik e Pfeffer (1974) }\end{array}$ \\
\hline Garbage can & $\begin{array}{l}\text { O processo decisório } \\
\text { apresenta uma configuração } \\
\text { altamente ambígua } \\
\text { denominada como "anarquia } \\
\text { organizada". } \\
\text { Decisores geralmente } \\
\text { possuem preferências mal } \\
\text { definidas e inconsistentes, } \\
\text { parcos conhecimentos sobre } \\
\text { meios e fins e apresentam } \\
\text { participação fluida no processo } \\
\text { decisório. }\end{array}$ & $\begin{array}{l}\text { Dada sua natureza anárquica, o } \\
\text { modelo sofre críticas sobre sua } \\
\text { aplicabilidade em níveis de } \\
\text { análise que distanciam-se do } \\
\text { indivíduo (grupal, } \\
\text { organizacional, inter } \\
\text { organizacional) e sua relevância } \\
\text { como um todo. } \\
\text { A abordagem ignora a } \\
\text { existência de conflitos mesmo } \\
\text { quando outras perspectivas } \\
\text { destacam sua existência nas } \\
\text { organizações. }\end{array}$ & $\begin{array}{l}\text { Cohen, March e Olsen } \\
\text { (1972) }\end{array}$ \\
\hline
\end{tabular}

Fonte: Adaptado de Eisenhardt e Zbaracki (1992).

A política, uma vez encarada como conjuntos de processos sócio-políticos nos quais ocorrem interações sociais entre indivíduos ao redor de certos problemas organizacionais independentemente da natureza dos objetivos (Royer \& Langley, 2008); proporcionaria então, um ambiente oportuno para o surgimento de coalizões e/ ou embates políticos. Para Child, Elbanna e Rodrigues (2010), a perspectiva política do processo decisório importa-se com as maneiras pelas quais partes interessadas podem afetar o processo e os resultados da tomada de decisão estratégica quer seja por meio do poder que possuem, quer seja por meio de medidas que tomem para exercer influência. Ainda segundo os autores, a perspectiva política foca-se em como e por quê indivíduos, grupos e 
organizações exercem poder ou acumulam influência de modo a moldar as decisões estratégicas que são realizadas em nome das organizações.

Assim, a perspectiva política (tal qual o modelo da racionalidade limitada) surge como uma reação aos modelos econômicos que têm como premissa básica o entendimento de que as organizações possuiriam um objetivo único. Para March (1962), as empresas são vistas como sistemas políticos que clarificam teorias econômicas convencionais, sugerindo assim, algumas formas de lidar com problemas clássicos na teoria dos sistemas políticos.

Para Allison (1971) a premissa básica da perspectiva política é a de que as organizações são coalizões de pessoas com interesses concorrentes. Ainda que estes indivíduos partilhem alguns objetivos em comum, como a sobrevivência da empresa, eles também apresentam conflitos. Esta premissa é considerada por Eisenhardt e Zbaracki (1992) como a primeira das três características que balizam a perspectiva política. March (1962) adiciona ainda que o cerne da perspectiva política é o processo pelo qual o conflito é resolvido entre indivíduos com preferências concorrentes.

Uma segunda característica do modelo político consiste na afirmação de que a escolha por certas alternativas em um processo decisório é reflexo das preferências dos autores mais poderosos presentes no processo. Um exemplo empírico que ressalta tal característica no contexto institucional pode ser encontrado no trabalho seminal de Salancik e Pfeffer (1974). Os autores investigam a relação entre o poder dos departamentos em uma instituição de ensino e a quantidade de recursos alocados. A conclusão apresentada pelos autores é a de que existe uma correlação positiva entre o poder do departamento (representado inclusive pelos indivíduos associados) e a aquisição de recursos escassos. Destaca-se ainda que esta correlação sobrepunha aspectos racionais como o número de cursos ou alunos atendidos por cada departamento.

A terceira característica associada ao modelo político é a afirmação de que pelo menos ocasionalmente, os indivíduos engajam-se em aspectos políticos. As "táticas" utilizadas pelos atores organizacionais para o engajamento político são discutidas por autores como Pfeffer e Salancik (2003), Pettigrew (1977) e Salancik e Pfeffer (1974) e têm como exemplos a formação de coalizões, o lobby, a cooptação e a retenção e controle de agendas (Eisenhardt \& Zbaracki, 1992).

As coalizões podem ser definidas como ações conjuntas entre duas ou mais pessoas com interesses semelhantes visando alterar o resultado relativo a outras pessoas (Zeitlin, 1975; Thibaut \& Kelley, 1959). Para Pfeffer e Salancik (2003), a própria concepção de uma organização incorreria na formação de uma coalizão, uma vez que sob o prisma da perspectiva política, uma organização só se mostraria viável enquanto seus incentivos são suficientes para elicitar as contribuições necessárias, ou em outras palavras, manter a coalizão de suporte.

Os autores ressaltam ainda que não existe uma regra formalmente estruturada para que um indivíduo adentre ou inicie a formação de uma coalizão. Tudo aquilo que justifique o envolvimento do participante é suficiente do ponto de vista da organização. Assim sendo, os participantes podem 
entrar em uma coalizão quando enxergam alguma vantagem em potencial e podem deixa-la quando não houver mais vantagem percebida (Pfeffer \& Salancik, 2003, p. 26).

A partir dos agrupamentos e engajamentos dos atores e suas coalizões emerge o jogo político interno à rotina organizacional. Para March (1962) e Fontenot e Wilson (1997) este jogo estaria calcado em constantes trocas de contribuições para incentivos. Contudo, amparando-se na premissa básica do modelo político, evidencia-se que estas trocas não se dão de uma maneira homogênea; incorrendo assim, em demandas concorrentes que deveriam ser mediadas por instâncias superiores aos grupos concorrentes.

Estas trocas garantiriam então às coalizões melhor posicionadas (aquelas que se saíram vitoriosas na disputa por demandas concorrentes), certo poder frente a outros participantes. O poder de um participante, enquanto função da dependência dos outros em relação às suas contribuições, atividades e capacidades (Emerson, 1962), também pode ser institucionalizado pelas ações intencionais daqueles que o detém através da formulação de regras, constituições, procedimentos e de sistemas de informação que limitem o potencial de ação de coalizões concorrentes, perpetuando assim, o seu controle (Pfeffer \& Salancik, 2003, p. 235).

Pfeffer e Salancik (2003) e Dimaggio e Powell (1983) destacam ainda que, em decorrência de tal relação de poder, aspectos como controle e influência emergiriam da interação entre os participantes organizacionais e o valor atribuído às contribuições realizadas e os incentivos demandados. O controle é definido como a habilidade de iniciar ou terminar ações a partir de um dado critério. Contudo, na prática, a relação entre poder e controle organizacional não seguiria critérios claramente estabelecidos (em contraposição aos modelos econômicos) e por vezes, verificase divergência na intensidade do controle exercido pela organização em certos participantes.

Neste sentido, alguns participantes que controlam recursos ou condições críticas para a organização, estariam em posição privilegiada de modo a influenciar suas ações. Pfeffer e Salancik (2003) ilustram tal situação como um controle social da organização e elencam as seguintes condições como facilitadoras para tal controle:

1. A posse de certo recurso pelo ator social;

2. A importância de certo recurso para a organização focal; sua criticidade para as atividades e sobrevivência da organização;

3. A inabilidade da organização focal em obter o recurso em outro lugar;

4. A visibilidade do controle do comportamento ou das atividades;

5. O critério do ator social na alocação, acesso e uso de recursos críticos;

6. O critério e a capacidade da organização focal em tomar a ação desejada;

7. A falta de controle sobre o recurso crítico por parte da organização focal; 
8. A habilidade do ator social em tornar conhecidas suas preferências para a organização focal.

Após a discussão dos elementos mais marcantes da dimensão política do processo decisório, a próxima seção apresenta o conceito e as características do processo de Sales and Operations Planning (S\&OP), para que posteriormente possa-se ilustrar a relação dos dois temas no estudo de caso proposto.

\subsection{O processo de planejamento de vendas e operações (Sales and Operations Planning - S\&OP)}

De acordo com a Association for Operations Management (APICS, 2011) o processo de Sales and Operations Planning (S\&OP) "tem por finalidade reconciliar, ajustar e comunicar os planos operacionais, financeiros e estratégicos de uma companhia transformando-os em um conjunto de números únicos". Tal feito se dá por meio da realização de reuniões contínuas e regulares, que buscam envolver todos os participantes no processo que estão alocados nas variadas áreas funcionais da organização.

Para Pedroso et al. (2016), estes participantes são liderados pela alta gerência da organização, que possui a responsabilidade de avaliar e revisar projeções, considerando o tempo para demanda, suprimentos, produtos, projetos estratégicos e planos financeiros, tendo como finalidade alinhar demanda e suprimentos. Mais especificamente, trata-se de um processo de planejamento conjunto com tomada de decisão que realinha os planos táticos das áreas funcionais da empresa a fim de auxiliar a organização no alcance de metas e objetivos do negócio (Lapide, 2005).

Bowersox, Closs, Cooper e Bowersox (2014) definem o S\&OP como um processo que coordena os planos de oferta e demanda em toda a empresa, que inclui o compartilhamento de informações e a definição de responsabilidades, visando desenvolver de forma sistemática um planejamento comum e coerente. Este planejamento, conforme destacam os autores, baseia-se em previsões, pedidos do cliente e promoções. As previsões se baseiam em informações de vendas e marketing, juntamente aos níveis históricos de atividade. Os pedidos do cliente incluem os pedidos atuais, as encomendas futuras já empenhadas e os contratos.

O processo de S\&OP tradicionalmente ocorre no decorrer de um mês sendo orientado a um horizonte de planejamento de 24 meses. Entretanto, há casos em que esse horizonte é reduzido para 6 meses de modo a minimizar erros de previsão e planejamento no plano mestre de produção (PMP). O processo de S\&OP envolve ainda a intermediação entre as esferas estratégicas e táticas das organizações uma vez que interliga os planos de Vendas, Marketing, P\&D, Manufatura, Compras e Finanças e facilita a comunicação, compartilhamento de informações e o planejamento entre áreas voltadas ao mercado como Vendas e Marketing e áreas como Manufatura e a Cadeia de Suprimentos (Esper, Defee, \& Mentzer, 2010; Pedroso et al., 2016). 
Dentre as características do S\&OP, Pedroso et al. (2016) ressaltam o planejamento de caráter tático, integrado e interfuncional na empresa e o seu horizonte de operação no médio prazo em que conecta o nível estratégico ao operacional. Esta integração ocorre tanto em âmbito vertical (do nível estratégico até o operacional) quanto horizontal. A integração horizontal ocorre entre decisões tomadas em um mesmo nível, envolvendo diferentes departamentos da empresa, tais como Marketing, manufatura e finanças, por exemplo (Corrêa, 2014).

Partindo desta estrutura de integração vertical e horizontal, Bowersox et al. (2014) descrevem o processo de S\&OP tradicionalmente realizado pelas empresas. Em um primeiro momento, o setor de finanças desenvolve planos de receita de vendas normalmente projetados para atender as expectativas dos acionistas. Posteriormente, o setor de vendas desenvolve planos e táticas de marketing para atender as metas de receita contemplando inclusive, planos de inovação, formação de preço e promoção para os produtos. Finalmente, a área de operações (leia-se produção, suprimentos e logística) desenvolve planos logísticos, de materiais e de produção que possam atender as demandas dos clientes considerando suas restrições operacionais e de seus parceiros na cadeia de suprimentos.

Os autores destacam ainda o surgimento de conflitos entre as áreas em função das tentativas de atendimento das demandas internas de cada um dos departamentos envolvidos no processo de S\&OP. Em particular, evidenciam as demandas concorrentes das áreas de vendas e operações; em que a primeira visa atender as solicitações exclusivas dos clientes enquanto a segunda pretende obter economias de escala em termos operacionais. A Figura 2 ilustra alguns dos conflitos entre as duas áreas. Os autores ainda descrevem em linhas gerais a natureza do conflito entre as duas áreas:

Figura 1 - Conflitos entre vendas e operações no processo de S\&OP

Balanceando objetivos

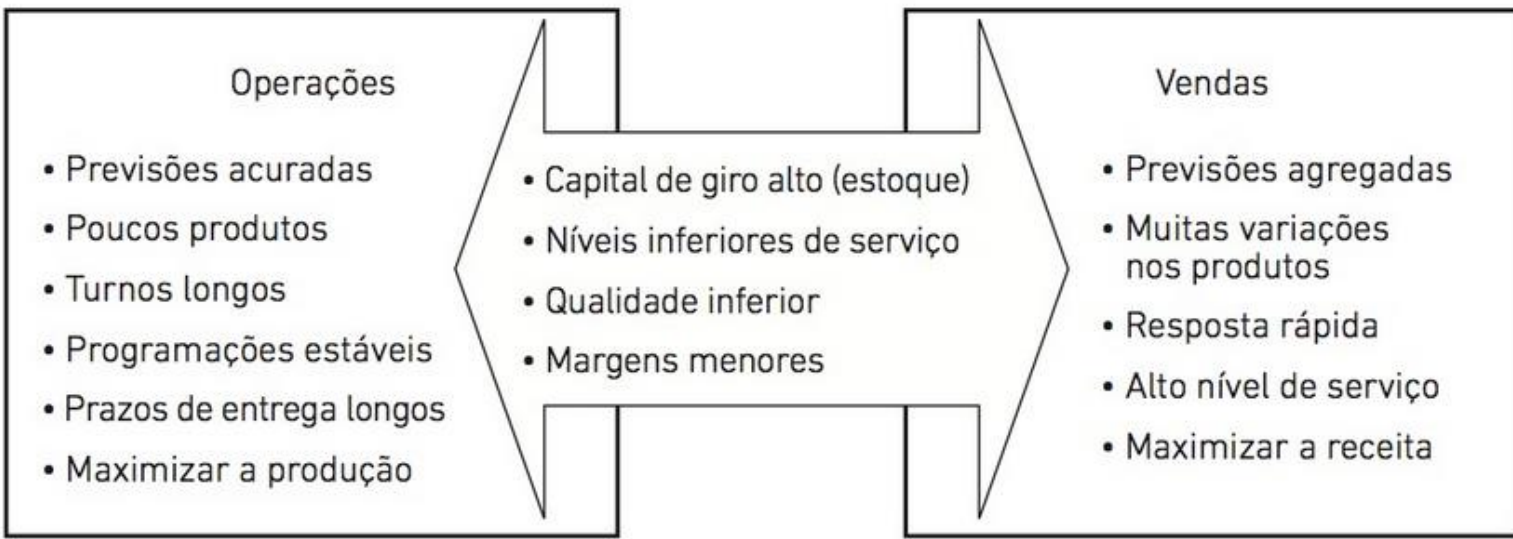

Abordagem funcional tradicional do planejamento leva a interesses distintos, ações não otimizadas e melhorias mais lentas

Fonte: Bowersox et al., 2014. 
Muito em função dos conflitos departamentais, é possível destacar que o processo de S\&OP faz emergir a necessidade de desenvolvimento de lideranças bem como de uma cultura adequada de planejamento e atendimento às demandas dentro da empresa (Tuomikangas \& Kaipia, 2014). Foi a partir deste cenário de disputas internas e necessidade de construção de lideranças que pretendeu-se evidenciar como os aspectos da dimensão política emergem e direcionam o processo de S\&OP. Para tanto, a próxima seção apresenta a metodologia utilizada para a análise, e em particular, os detalhes do estudo de caso realizado.

\section{Metodologia}

De modo a atender os objetivos propostos no artigo, optou-se como método de pesquisa o estudo de caso qualitativo (Godoy, 2010; Eisenhardt, 1989). De acordo com Yin (2005) e Eisenhardt (1989), o estudo de caso pode ser considerado um tipo de pesquisa de natureza empírica que consiste no exame de uma ou poucas unidades, de modo a prover entendimento sobre um fenômeno. Utilizado para a descrição de um fenômeno, testar ou gerar teorias, o estudo de caso é potencialmente eficaz na captura do fenômeno estudado uma vez que permite o entendimento deste em seu contexto.

A escolha da abordagem vem para atender uma demanda latente por trabalhos de natureza qualitativa no campo de operações em função da crescente complexidade dos seus fenômenos (Barratt, Choi, \& Li, 2011; Baxter, Goffin, \& Szwejczewski, 2014; Fremeth et al., 2016; Golicic \& Davis, 2012; Runfola, Perna, Baraldi, \& Gregori, 2017). A partir da escolha do método de estudo de caso, foi possível investigar a formação de coalizões políticas em duas empresas do ramo alimentício em meio aos seus respectivos processos de S\&OP. Além disso, foi possível evidenciar alguns outros gaps e oportunidades de trabalhos futuros que serão posteriormente comentados.

As duas empresas selecionadas para o estudo de caso, apesar de pertencerem ao mesmo segmento industrial (alimentos e bebidas), apresentavam características gerenciais e operacionais distintas, como por exemplo, a composição da alta gerência, mercados de atuação e porte. A amostra escolhida por conveniência baseou-se não só no acesso do pesquisador, mas também no seu conhecimento sobre seus processos, suas rotinas operacionais e padrões de gerenciamento. Ademais, conforme pode ser observado nas seções de análise e conclusão, algumas dessas características deram margem a discussões em termos da influência de certas variáveis de controle e propostas de trabalhos futuros.

A coleta de dados se deu a partir de entrevistas semiestruturadas com membros das áreas de vendas, logística e produção, observação in loco e análise documental. Cabe ressaltar que tanto as entrevistas, quanto as observações não se deram de maneira linear em cada uma das empresas investigadas. Demandando do pesquisador uma série de visitas às unidades fabris, acompanhamento de reuniões (shadowing) e conversas informais transcorridas ao longo de seis meses. As entrevistas 
semiestruturadas foram realizadas individualmente com membros das duas empresas e que ocupavam cargos em diferentes setores e com diferentes posições hierárquicas. Assim, a amostra foi composta por um diretor industrial, cinco gerentes (sendo dois de produção, um de logística, um de vendas e um de planejamento) e seis analistas (dois de logística/ suprimentos, dois de produção e dois de vendas). A Figura 3 apresenta a composição da amostra.

Figura 3 - Composição da amostra

\begin{tabular}{|l|l|l|l|}
\hline Respondente & Função & Área & Empresa \\
\hline DIR_1 & Diretor & Industrial & ALFA \\
\hline GER_1 & Gerente & Produção & ALFA \\
\hline GER_2 & Gerente & Planejamento & ALFA \\
\hline GER_3 & Gerente & Logística & ALFA \\
\hline ANA_1 & Analista & Logística & ALFA \\
\hline ANA_2 & Analista & Vendas & ALFA \\
\hline GER_4 & Gerente & Produção & BETA \\
\hline GER_5 & Gerente & Vendas & BETA \\
\hline ANA_3 & Analista & Produção & BETA \\
\hline ANA_4 & Analista & Produção & BETA \\
\hline ANA_5 & Analista & Vendas & BETA \\
\hline ANA_6 & Analista & Suprimentos & BETA \\
\hline
\end{tabular}

Fonte: Dados da pesquisa.

Os dados coletados foram analisados por meio da técnica de análise de conteúdo (Bardin, 2011), considerando tanto a análise individual dos casos (within-case analysis) quanto a análise conjunta dos casos (cross-case analysis) (EISENHARDT, 1989). Para a realização da análise, foram utilizadas categorias advindas da literatura e do próprio discurso dos entrevistados. As categorias derivadas da literatura que subsidiaram a análise (bem como a construção do roteiro de entrevistas) foram: (i) processo político, (ii) relações interpessoais, (iii) formação de coalizões e (iv) influência e controle (Dimaggio \& Powell, 1991; Emerson, 1962; Powell \& Bromley, 2015; Scott, 2008). Além destas categorias, os relatos dos entrevistados revelaram uma nova categoria de análise aqui denominada de $(v)$ rumos estratégicos. Esta categoria contemplou a visão dos entrevistados (em especial, dos analistas) sobre a forma com que a empresa seria direcionada em termos de atendimento de demandas internas e externas em função da estratégia adotada pelos seus gestores.

As entrevistas foram gravadas com autorização dos respondentes e posteriormente transcritas. As transcrições foram então analisadas com o auxílio do software Atlas.ti ${ }^{\bullet}$ de acordo com as categorias previamente mencionadas. De posse das análises dos discursos dos entrevistados, passou-se à construção das relações entre as categorias de análise e, por fim, à análise (individual e conjunta) dos casos propriamente dita. 
A Figura 4 ilustra o percurso metodológico da pesquisa.

Figura 4 - Percurso metodológico da pesquisa.

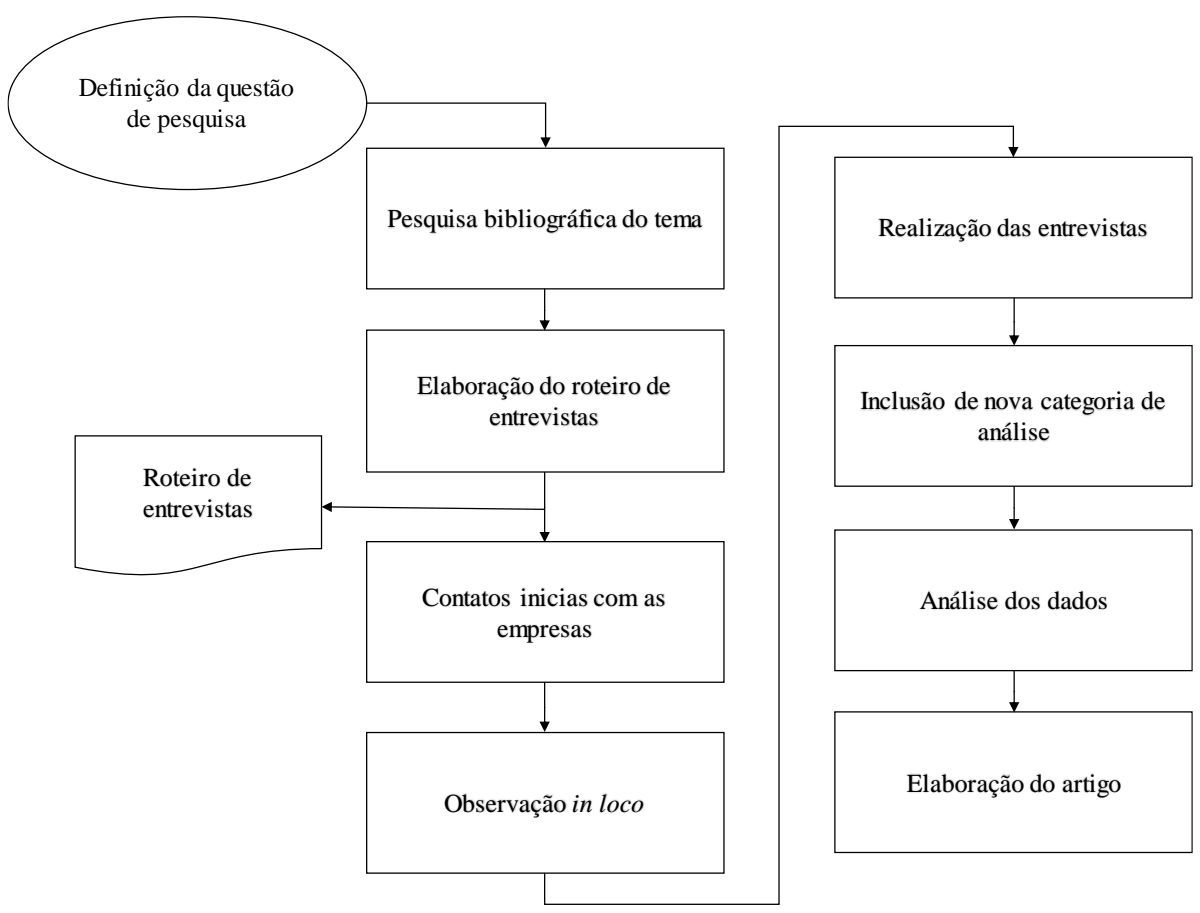

Fonte: Dados da pesquisa.

\section{Análise dos casos}

Conforme previamente citado, o estudo dos dois casos teve por objetivo a análise da influência do processo político, e em particular, a formação de coalizões políticas em meio ao processo de S\&OP em duas empresas do setor alimentício. Por questões éticas e de sigilo, algumas informações referentes aos resultados operacionais e financeiros, bem como opções estratégicas dessas empresas foram suprimidas. Da mesma forma, os próprios nomes das empresas foram substituídos por denominações que não as revelem. Assim, as empresas foram denominadas de ALFA e BETA e todas as informações abordadas aqui e descrições realizadas foram construídas de modo a não caracteriza-las ou denegri-las.

As empresas apresentaram aspectos muito diferentes em termos operacionais e de estruturação. Enquanto a empresa ALFA atuava em todo o território nacional com 9 unidades industriais localizadas nas regiões Nordeste, Sudeste e Sul do país, com mais de 3.000 funcionários, a empresa BETA tinha atuação focalizada na região Nordeste e contava com apenas uma unidade fabril operando com cerca de 300 funcionários.

Os segmentos de atuação das empresas, suas respectivas fatias de mercado e concorrentes também divergiram consideravelmente. A empresa ALFA, por atuar com um portfólio de produtos amplo, apresentava produtos que atendiam as necessidades de clientes das classes A, B e C. Os 
produtos da empresa BETA por sua vez, estavam alinhados ao atendimento de demandas associadas às classes C e D. Em relação à competição no mercado ALFA apresentava aproximadamente $25 \%$ do mercado consumidor, figurando como segundo maior competidor do seu segmento. Já a empresa BETA era líder de mercado no seu segmento na região Nordeste, concentrando à época $58 \%$ do mercado, segundo dados do website da própria empresa.

A estrutura hierárquica e de tomada de decisão das empresas também foi um fator a ser levado em consideração. À época da coleta e análise dos dados, ALFA já havia passado do caráter de empresa familiar tradicional, para uma estrutura mais competitiva com seu mercado. Há menos de 18 meses a empresa havia implementado uma reestruturação nas suas gerências e diretorias a partir da contratação de profissionais com experiência em empresas como Parmalat e Ambev. Contrariamente, BETA mantinha desde sua fundação, há aproximadamente 65 anos, uma estrutura de empresa familiar tradicional concentrada na figura do seu fundador e proprietário.

Apesar destas diferenças os organogramas das duas empresas apresentaram forte similaridade. Foi possível verificar a mesma estrutura departamental em cada uma das 9 unidades de ALFA e na unidade produtora da empresa BETA. As empresas contavam com uma estrutura clássica de departamentos que se subdividiam em grandes ramos como industrial, administrativo-financeiro e comercial. A Figura 5 apresenta as características gerais das empresas investigadas.

Figura 5 - Características gerais das empresas

Empresa

Unidades produtivas

Localização

Atuação

Segmento (classes)

Número de funcionários

Posição no mercado

Market share

Fonte: Dados da pesquisa.
BETA

1

Nordeste, Sudeste e Sul Nordeste

Nacional Regional (Nordeste)

A, B e C C e D

$3000 \quad 300$

2oㄴ Líder

$25 \%$

$58 \%$

A partir das observações foi possível evidenciar diferentes dinâmicas para a formação das coalizões em cada uma das organizações investigadas. Cada uma dessas dinâmicas, sendo motivadas por elementos particulares decorrentes de aspectos como estilo gerencial, intenção de posicionamento no mercado e conhecimento técnico dos atores organizacionais.

Antes de tudo, cabe salientar que o reflexo das coalizões e seus respectivos controles puderam ser percebidos não em uma única decisão, mas sim, em um conjunto de decisões associadas ao nível de atendimento às demandas mensais por cada empresa em questão. Em termos gerais, os volumes de produção, vendas e transporte eram influenciados pelas ações destas coalizões. Por conseguinte, as decisões associadas a tais volumes eram desdobradas nos resultados mensais 
(monitorados por meio de Key Performance Indicators - KPIs) de cada um dos departamentos envolvidos no processo de S\&OP e das organizações como um todo.

A empresa ALFA que à época, passava por um processo de manutenção da sua posição de mercado em meio a uma expansão da sua arquitetura organizacional, em função da adoção de uma estratégia de diversificação, procurava cada vez mais expandir sua carteira de clientes e sua participação no mercado (market share), em especial na região Sudeste. Assim, o que percebeu-se foi um empoderamento da área comercial ao passo que as metas globais da empresa previam tal expansão em um período de dois anos.

Afora o foco suportado pela opção estratégica da empresa, a área comercial contava com o apoio da área administrativa-financeira mediante a ação dos controllers e a frequente emissão dos relatórios de resultados. Neste ponto, foi possível perceber a formação de uma coalizão entre as duas áreas de modo a garantir não só o controle das informações, mas também o formato de sua divulgação.

Os impactos percebidos na ação desta coalizão puderam ser percebidos diretamente no processo de S\&OP na medida em que o planejamento muitas vezes fora orientado para o atendimento de demandas particulares da região Sudeste (principal alvo da expansão da empresa e base de operações das áreas de controladoria e comercial) em detrimento à eficiência operacional das unidades fabris. Mais especificamente, o planejamento foi norteado para a produção de itens com baixo volume, mas com maior valor agregado. Estas decisões incorreram não só em baixa ocupação de linhas de produção da região Nordeste dedicadas à produção de produtos de menor valor agregado, mas também no aumento dos custos logísticos associados à reposição de estoques em fábricas e centros de distribuição.

Outros impactos desta configuração puderam ser percebidos nas áreas de suporte à função de produção, como manutenção e qualidade. Dado que o planejamento impactava consideravelmente a taxa de ocupação das linhas de produção, ora em maior carga, ora em total ociosidade, as áreas de suporte não puderam realizar o planejamento de suas atividades de maneira adequada; consequentemente sofrendo impactos nas suas ações de programação e execução de atividades. Os custos de manutenção não puderam ser programados adequadamente, o que resultou em orçamentos que não puderam ser cumpridos e alocações de hora-homem que não foram efetivadas.

Ainda mais crítica fora a situação de algumas coordenações de qualidade que, em função da necessidade de abastecimento emergencial de certos produtos (para o atendimento de demandas específicas de grandes grupos varejistas, denominados pela empresa ALFA de Grandes Marcas), tiveram que abdicar de algumas etapas do processo de inspeção de produto acabado; como por exemplo, a inspeção de shelf life.

Apesar de todos impactos negativos observados na rotina da empresa ALFA e listados aqui, ficou evidenciado que em função ( $i$ ) do acesso que as áreas comercial e administrativo-financeira 
possuíam aos membros da diretoria geral e da presidência, refletido aqui pelo relacionamento interpessoal dos seus gerentes e diretores e (ii) da estrutura do sistema de bonificação adotado pela empresa, que estava fortemente calcada nas metas de expansão do market share, que a coalizão formada por essas duas diretorias mantinha o controle social da organização. Pois, por mais que diariamente as ações da coalizão limitassem as ações das demais áreas, era perceptível o interesse de que a empresa como um todo apresentasse resultados que garantissem a distribuição de bônus ao final do ano fiscal.

Na empresa BETA, a situação observada foi bem diferente. A presença de um fundador no dia a dia de suas operações conferia-Ihe uma grande concentração no processo de tomada de decisão em todas as suas instâncias. Desde a aquisição de um equipamento para a área de produção, até o processo de desenvolvimento de um novo produto sofria influência ou controle por parte do proprietário da empresa. Situação esta que em muitas vezes, traduzia-se em perda de prazos no atendimento de pedidos já colocados em carteira.

Por atender um mercado com demandas mais baixas em termos de qualidade, em que o preço figurava como critério qualificador e ganhador de pedidos (Slack, Chambers \& Johnston, 2009), a estratégia da empresa BETA focava-se no estabelecimento de custos baixos e eficiência operacional. Assim sendo, a orientação no processo de S\&OP (que era tratado como um PCP de médio prazo que envolvia também as áreas de vendas e logística) era a de alocação máxima das linhas de produção.

Apesar dessa estratégia garantir em termos práticos menores custos operacionais, observouse como reflexo uma série de eventos de não atendimento à demanda da área comercial. Estes eventos (e seus reflexos) puderam ser observados por exemplo, no mês de Outubro de 2014 quando o KPI de planejamento de vendas atingiu seu menor valor desde que começou a ser monitorado. À época, $18 \%$ dos pedidos implantados durante o mês deixaram de ser atendidos por indisponibilidade da área de operações. Cabe aqui a ressalva, que estes pedidos respondiam por demandas já firmadas junto a clientes tradicionais da empresa e que consistiam em grandes varejistas da região.

Em termos mais específicos, a dinâmica do não atendimento consistia no resultado da coalizão formada dentro da área industrial (produção e PCP), juntamente com a alta gestão da empresa BETA. Entendendo que a alta ocupação das linhas de produção garantiria menores custos operacionais, e consequentemente, saúde financeira ao final do mês, o proprietário da empresa direcionava (inclusive de forma mandatória) a área industrial para que não houvesse paradas de produção. Fossem estas paradas originadas via planejamento de manutenção ou eventuais setups.

Orientados a não realizar trocas de produção (setups) e amparados pela relação próxima que mantêm com o proprietário, os gestores da área de produção mantinham as linhas produzindo aqueles produtos previamente programados, aumentando consideravelmente seus volumes no estoque e impactando no percentual de atendimento à demanda da área comercial. Não obstante o cenário já descrito, outro fato que chamava a atenção na rotina das operações era o controle das 
informações relacionadas aos volumes de produção, estoque e demanda de vendas. Os três valores frequentemente não coincidiam e a decisão final sobre qual valor deveria ser atendido, logicamente favorecia a posição da coalizão dominante (Pfeffer \& Salancik, 2003).

Após a apresentação das análises individuais e conjunta dos casos, foi possível elaborar a Figura 6 que sintetiza os achados em cada uma das empresas e associa-os às categorias de análise (Godoy, 2010; Bardin, 2011).

Figura 6 - Síntese dos resultados

Empresa Dimensão política
Coalizões Mecanismos de controle

ALFA

Os atores organizacionais utilizam a influência e as relações interpessoais como vetores para a condução do processo político e modificação dos rumos da organização de forma a favorecê-los; possuindo assim, o controle social da tomada de decisão.

BETA

Fonte: Dados da pesquisa.

\section{Conclusões}

Após a estruturação de um referencial teórico em que ressaltaram-se os aspectos das dimensão política do processo decisório e as características mais marcantes do processo de S\&OP, um estudo de caso de natureza qualitativa foi apresentado para ilustrar os principais efeitos desta configuração na rotina e resultados de duas diferentes empresas do setor de alimentos e bebidas.

A partir da análise de conteúdo qualitativo dos dados coletados mediante observações, entrevistas semiestruturadas e análise documental nas duas empresas, foi possível evidenciar a existência de características preconizadas nas categorias de análise derivadas da literatura selecionada e também daquela decorrente dos relatos dos entrevistados. O elemento político pode ser percebido ao longo de todo o processo de S\&OP das duas empresas na medida em que atores organizacionais se utilizavam de sua posição e influência (em ambos os casos as relações interpessoais destacam-se 
como vetores para a condução do processo político) para modificar os rumos da organização em seus vários níveis e horizontes de atuação.

A formação de coalizões também foi percebida em ambas as empresas, contudo, ressalta-se que o fenômeno foi fortemente influenciado por aspectos particulares de cada empresa, como suas arquiteturas organizacionais (refletidas em termos de hierarquia e porte) e escolhas estratégicas. A representação das empresas em seus mercados de atuação, seu posicionamento frente aos concorrentes e o nível de exigência de seus clientes também puderam ser destacados como fatores associados à formação de coalizões internas às organizações.

Adicionalmente, foram analisados os mecanismos de controle desenvolvidos e utilizados por cada uma das coalizões observadas. Enquanto as coalizões da empresa ALFA faziam uso do sistema de bonificações como mecanismo de controle, no caso da empresa BETA, notabilizou-se o fato de que o próprio fundador e proprietário da empresa coadunava com a manutenção da coalizão dominante e com seus métodos de controle para a tomada de decisões.

Apesar de tentar abranger e elicitar ao máximo as características propostas na literatura do modelo político do processo decisório ao mesmo tempo em que aproximava-as do processo de S\&OP por meio da ilustração de dois casos, entende-se que este trabalho apresentou algumas limitações. A primeira delas, diz respeito à análise dos dados coletados. Apesar do interesse em trabalhar mais profundamente os discursos dos atores sociais envolvidos, o tempo para a elaboração deste artigo e o acordo firmado entre as partes só permitiu a realização de conversas informais e entrevistas com parte das equipes de vendas.

A segunda limitação está associada à ênfase dada à tática de formação de coalizões neste trabalho. A opção por limitar-se apenas à formação de coalizões se deu como uma tentativa de clarificar ao máximo, aquela que se entende como a mais recorrente das táticas do modelo político dentro das organizações. Contudo, fica aqui a oportunidade para a elaboração de trabalhos futuros concernentes ao tema.

Além das dinâmicas de coalizão enxergadas durante o processo, foi possível verificar (mesmo que de forma sutil e incipiente) elementos de cooptação nas ações de departamentos posicionados em meio ao "fogo cruzado" das coalizões analisadas. Para o caso da empresa ALFA este efeito pode ser percebido na área de compras, que apesar de estar diretamente ligada ao atendimento das demandas internas da área industrial (em particular das áreas de manutenção e produção), respondia hierarquicamente à área administrativo-financeira, componente da coalizão dominante. Já na empresa BETA, o efeito foi visualizado nas ações e no discurso dos gestores da área de logística, uma vez que mantinham interface direta com a área de produção (através do PCP e da armazenagem) assim como com a área de vendas (através do processo de entrega de produtos acabados aos clientes) 
A partir da análise destes resultados foi possível estabelecer uma ponte com alguns aspectos observados na teoria (neo) institucional (Dimaggio \& Powell, 1983; Scott, 2008), no sentido de nortear a compreensão de fenômenos complexos associados às organizações. Particularmente, observou-se que o entendimento da estratégia como um suporte para a formação e manutenção das coalizões e dos seus respectivos mecanismos de controle poderia ser melhor investigado sob o prisma da legitimidade. De fato, os resultados indicaram que o alinhamento dos interesses das coalizões à estratégia vigente conferia às coalizões uma legitimidade (Grenwood, Oliver, Suddaby, \& SahlinAndersson, 2008; Suddaby \& Greenwood, 2005) observada em todos os níveis da empresa. Logo, propõem-se a título de trabalhos futuros um aprofundamento nas investigações sobre os efeitos dessa legitimidade nas decisões organizacionais e na concentração de poder (Deephouse \& Suchman, 2008; Lawrence, 2008)

Incorpora-se a essa proposta, a ideia de construção de um framework que integre as componentes aqui apresentadas e discutidas de maneira a suscitar um melhor entendimento de suas relações e efeitos nos resultados do processo decisório nos mais diferentes níveis organizacionais. Pode-se pensar em abordagens que partam de modelos de equações estruturais (MEE) como diagramas de caminho ou regressão linear múltipla que associem os aspectos aqui abordados a fenômenos como a assimetria da informação ou a transferência de conhecimento. Uma outra proposta para trabalhos futuros poderia ser a realização de focus groups com gestores responsáveis pelo processo de S\&OP de forma a evidenciar os fatores limitantes e motivadores para a formação de coalizões dentro das organizações.

Por fim, entende-se que o trabalho apresentou contribuições não só àqueles que atuam profissionalmente junto a processos de $\mathrm{S} \& \mathrm{OP}$, mas também àqueles que debruçam-se teoricamente sobre o tema. Neste sentido, ressalta-se que os resultados aqui apresentados corroboram estudos que elicitam a relação entre o processo de S\&OP e as escolhas estratégicas das empresas (Pedroso et al., 2016; Thomé et al., 2014; Tuomikangas \& Kaipia, 2014). Mais que isso, encontram-se em linha com posicionamentos recentes de pesquisadores da área que defendem uma análise mais contextualizada do processo de S\&OP, levando em consideração não apenas aspectos técnicos e processuais, mas também elementos comportamentais que garantirão maior enfoque à complexidade inerente aos fenômenos da área de operações (Kristensen \& Jonsson, 2018; Rajkumar, Kavin, Luo, \& Stentoft, 2016; Tsanos \& Zografos, 2016).

\section{Referências}

Allison, G. T. (1971). Essence of Decision: Explaining the Cuban Missile Crisis. Boston: Little, Brown \& Company.

APICS - The Association for Operations Management (2011). APICS Operations Management Body of Knowledge Framework. 3a ed. Chicago: APICS The Association for Operations Management. 
Bardin, L. (2011). Análise De Conteúdo. São Paulo. https://doi.org/10.1017/CBO9781107415324.004

Barratt, M., Choi, T., \& Li, M. (2011). Qualitative case studies in operations management: Trends, research outcomes, and future research implications. Journal of Operations Management, 29(4), 329-342. https://doi.org/doi: 10.1016/j.jom.2010.06.002

Baxter, D. I., Goffin, K., \& Szwejczewski, M. (2014). The repertory grid technique as a customer insight method. Research-Technology Management, 57(4), 35-42.

https://doi.org/10.5437/08956308X5704229

Bower, P. (2012). Integrated Business Planning: Is It a Hoax or Here to Stay? Journal of Business Forecasting, 31(1), 11-17.

Bowersox, D. J., Closs, D. J., Copper, M. B., \& Bowersox, J. C. (2014). Gestão logística da cadeia de suprimentos. 4a ed. Porto Alegre: Bookman.

Child, J., Elbanna, S., \& Rodrigues, S. (2010). The Political Aspects of Strategic Decision Making. (P. C. Nutt \& D. C. Wilson, Orgs.), Handbook of Decision Making. Hoboken: John Wiley \& Sons.

Corrêa, H. L. (2014). Administração de cadeia de suprimentos e logística: o essencial. São Paulo: Atlas.

Deephouse, D. L. \& Suchman, M. (2008) Legitimacy in Organizational Institutionalism. In: Greenwood, R., Oliver, C., Suddaby, R., \& Sahlin- Andersson, K. (editors), The SAGE Handbook of Organizational institutionalism. Thousand Oaks: SAGE Publications Inc.

Dimaggio, P. J., \& Powell, W. W. (1983). The iron cage revisited: Institutional and collective rationality in organizational fields. American Sociological Review. https://doi.org/10.2307/2095101

Dimaggio, P., \& Powell, W. (1991). The New Institutionalism in organizational analysis. The International Encyclopedia of Organization Studies, 144-145. https://doi.org/10.1002/asi

Dubois, A., \& Salmi, A. (2016). A call for broadening the range of approaches to case studies in purchasing and supply management. Journal of Purchasing and Supply Management, 22(4), 247249. https://doi.org/10.1016/j.pursup.2016.09.002

Eisenhardt, K. M. (1989). Building Theories from Case Study Research. Academy of Management Review, 14 (4), 532-550.

Eisenhardt, K. M., \& Zbaracki, M. J. (1992) Strategic decision management. Strategic Management Journal, 13 (Special Issue: Fundamental Themes in Strategy Process Research), 17-37.

Elbanna, S., Kapoutsis, I., \& Mellahi, K. (2017). Creativity and propitiousness in strategic decision making: The role of positive politics and macro-economic uncertainty. Management Decision, 0000. https://doi.org/10.1108/MD-02-2017-0113

Emerson, R. M. (1962). Power-Dependence Relations. American Sociological Review, 27(1), 31. https://doi.org/10.2307/2089716

Esper, T. L., Defee, C. C., \& Mentzer, J. T. (2010). A framework of supply chain orientation. The International Journal of Logistics Management, 21(2), 161-179. https://doi.org/10.1108/09574091011071906

Fontenot, R. J., \& Wilson, E. J. (1997). Relational exchange: A review of selected models for a prediction matrix of relationship activities. Journal of Business Research, 39(1), 5-12. 
https://doi.org/10.1016/S0148-2963(96)00156-7

Fremeth, A. R., Holburn, G. L. F., \& Richter, B. K. (2016). Bridging Qualitative and Quantitative Methods in Organizational Research: Applications of Synthetic Control Methodology in the U.S. Automobile Industry. Organization Science. https://doi.org/10.1287/orsc.2015.1034

Godoy, A. S. (2010) Estudo de caso qualitativo. In: Godoi, C. K., Bandeira-de-Mello, R., \& Silva, A. B. (org.) Pesquisa qualitativa em estudos organizacionais: paradigmas, estratégias e métodos. 2a ed. São Paulo: Saraiva.

Golicic, S. L., \& Davis, D. F. (2012). Implementing mixed methods research in supply chain management. International Journal of Physical Distribution \& Logistics Management, 42(8/9), 726741. https://doi.org/10.1108/09600031211269721

Grenwood, R., Oliver, C., Suddaby, R., \& Sahlin-Andersson, K. (2008). The SAGE Handbook of Organizational institutionalism. The SAGE Handbook of Organizational institutionalism. Thousand Oaks: SAGE Publications Inc.

Grimson, J. A., \& Pyke, D. F. (2007). Sales and operations planning: an exploratory study and framework. The International Journal of Logistics Management, 18(3), 322-346.

https://doi.org/10.1108/09574090710835093

Hiatt, S. R., \& Sine, W. D. (2014). Clear and present danger: Planning and new venture survival amid political and civil violence. Strategic Management Journal, 35, 773-785.

https://doi.org/10.1002/smj

Jacobs, F. R., Berry, W., Whybark, D. C., \& Vollman, T. (2010). Manufacturing Planning and Control for Supply Chain Management.

Kristensen, J., \& Jonsson, P. (2018). Context-based sales and operations planning (S\&OP) research: A literature review and future agenda. International Journal of Physical Distribution \& Logistics Management, 48(1), 19-46. https://doi.org/10.1108/IJPDLM-11-2017-0352

Lapide, B. (2005). Sales and operations planning part III: a diagnostic model. The Journal of Business Forecasting, Spring(1), 13-16. https://doi.org/10.1108/JRIM-08-2013-0059

Lawrence, T. B. (2008). Power, Institutions and Organizations. In: Greenwood, R., Oliver, C., Suddaby, R., \& Sahlin- Andersson, K. (editors), The SAGE Handbook of Organizational institutionalism. Thousand Oaks: SAGE Publications Inc.

March, J. G. (1962). The business firm as a political coalition. The Journal of Politics, 24 (4), 662-678.

Mintzberg, H., Raisinghani, D. \& Théorêt, A. (1976) The structure of "unstructured" decision processes. Administrative Science Quarterly, 21, 246 - 275.

Molm, L. D. (1997). Coercive Power in Social Exchange.

Noroozi, S., \& Wikner, J. (2017). Sales and operations planning in the process industry: A literature review. International Journal of Production Economics, 188(April 2016), 139-155. https://doi.org/10.1016/j.ijpe.2017.03.006

Nutt, P. C. (2008). Investigating the Success of Decision Making Processes: Success of Decision Making Processes. Journal of Management Studies, 45(2), 425-455. https://doi.org/10.1111/j.14676486.2007.00756.x 
Pedroso, C. B., da Silva, A. L., \& Tate, W. L. (2016). Sales and Operations Planning (S\&OP): Insights from a multi-case study of Brazilian Organizations. International Journal of Production Economics, 182, 213-229. https://doi.org/10.1016/j.ijpe.2016.08.035

Pettigrew, A. M. (1977). Strategy Formulation as a Political Process. International Studies of Management \& Organization, 7(2), 78-87. https://doi.org/10.1080/00208825.1977.11656228

Pfeffer, J., \& Salancik, G. R. (2003). The external control of organizations. Stanford, California: Stanford University Press.

Powell, W. W., \& Bromley, P. (2015). New Institutionalism in the Analysis of Complex Organizations. In: International Encyclopedia of the Social \& Behavioral Sciences (p. 764-769). https://doi.org/10.1016/B978-0-08-097086-8.32181-X

Proud, J. F. (2007). Master scheduling: A practical guide to competitive manufacturing ( $\left.3^{\circ} \mathrm{ed}\right)$. Hoboken: John Wiley \& Sons. https://doi.org/10.1016/0305-0483(93)90092-Y

Rajkumar, C., Kavin, L., Luo, X., \& Stentoft, J. (2016). Doctoral dissertations in logistics and supply chain management: a review of Nordic contributions from 2009 to 2014. Logistics Research, 9(1), 1-18. https://doi.org/10.1007/s12159-016-0132-0

Royer, I., \& Langley, A. (2008). Linking Rationality, Politics and Routines in Organizational Decision Making, in: The Oxford Handbook of Organizational Decision Making, Hodgkinson G. P. \& Starbuck, W. H. (Eds), 250-270.

Runfola, A., Perna, A., Baraldi, E., \& Gregori, G. L. (2017). The use of qualitative case studies in top business and management journals: A quantitative analysis of recent patterns. European Management Journal, 35(1), 116-127. https://doi.org/10.1016/j.emj.2016.04.001

Salancik, G. R., \& Pfeffer, J. (1974). The Bases and Use of Power in Organizational Decision Making: The Case of a University. Administrative Science Quarterly, 19 (4), 453-473.

Scott, W. R. (2008). Institutions and Organizations: Ideas and Interests ( $3^{\circ}$ ed). Thousand Oaks, California: SAGE. https://doi.org/10.1017/CBO9781107415324.004

Simon, H. A. (1965). Comportamento administrativo: estudo dos processos decisórios nas organizações. 2a ed. Rio de Janeiro: Fundação Getúlio Vargas.

Slack, N., Chambers, S., \& Johnston, R. (2009) Administração da produção. 3. ed. São Paulo: Atlas.

Suddaby, R., \& Greenwood, R. (2005). Rhetorical Strategies of Legitimacy. Administrative Science Quarterly, 50(1), 35-67. https://doi.org/10.2189/asqu.2005.50.1.35

Thibaut, J. W. \& Kelley, H. H. (1959). The social psychology of groups. New York: John Wiley \& Sons.

Thomé, A. M. T., Scavarda, L. F., Fernandez, N. S., \& Scavarda, A. J. (2012). Sales and operations planning: A research synthesis. International Journal of Production Economics, 138(1), 1-13. https://doi.org/10.1016/j.ijpe.2011.11.027

Thomé, A. M. T., Scavarda, L. F., Pires, S. R. I., Ceryno, P., \& Klingebiel, K. (2014). A multi-tier study on supply chain flexibility in the automotive industry. International Journal of Production Economics, 158, 91-105. https://doi.org/10.1016/j.ijpe.2014.07.024

Tsanos, C. S., \& Zografos, K. G. (2016). The effects of behavioural supply chain relationship 
antecedents on integration and performance. Supply Chain Management: An International Journal, 21(6), 678-693. https://doi.org/10.1108/SCM-06-2016-0211

Tsotsolas, N., \& Alexopoulos, S. (2017). Towards a holistic strategic framework for applying robust facilitated approaches in political decision making. Operational Research, 1-41.

https://doi.org/10.1007/s12351-017-0295-8

Tuomikangas, N., \& Kaipia, R. (2014). A coordination framework for sales and operations planning (S\&OP): Synthesis from the literature. International Journal of Production Economics, 154, 243-262. https://doi.org/10.1016/j.ijpe.2014.04.026

Yin, R. K. (2005). Estudo de caso: planejamento e métodos. 2a ed. Porto Alegre: Bookman.

Zeitlin, M. P. (1975). Coalizões: como se formam e como surge o conflito. Revista de Administração de Empresas - RAE, 15 (1), 47-53.

Recebido em: 30 maio 2018 / Aprovado em: 21 jan. 2020

Para referenciar este texto

American Psychological Association (APA)

Gomes, G. R. S. (2020, out./dez.). A influência da dimensão política no processo de Sales and Operations Planning (S\&OP). Exacta, 18(4), 908-929. https://doi.org/10.5585/exactaep.v18n4.8736. 